\title{
Balloon Catheter Rated Burst Pressure
}

National Cancer Institute

\section{Source}

National Cancer Institute. Balloon Catheter Rated Burst Pressure. NCI Thesaurus. Code C150164.

Calculated pressure at which a balloon would not be expected to burst. Based on an appropriate confidence and reliability from measured burst pressures. 